\title{
A AUDIÊNCIA JUDICIAL EM AÇÃO: UMA ETNOGRAFIA DAS INTERAÇÕES ENTRE JURISTAS E JURISDICIONADOS NA FRANÇA*
}

\author{
Pedro Heitor Barros Geraldo
}

THE JUDICIAL HEARING IN ACTION: AN ETNOGRAPHY OF THE INTERACTIONS BETWEEN JURISTS AND LAY PEOPLE

\section{RESUMO}

ESTE ARTIGO PROCURA DESCREVER AS INTERAÇŌES ENTRE JURISTAS E LEIGOS NOS FÓRUNS. AS AUDIÊNCIAS JUDICIAIS SÃO UM AMBIENTE INTERESSANTE ONDE PODEMOS OBSERVAR ESSAS INTERAÇÕES ENTRE PROFISSIONAIS E LEIGOS. A PESQUISA DE CAMPO É BASEADA NA OBSERVAÇÃO DE AUDIÊNCIAS DE JUÍZES DE PROXIMIDADE EM FÓRUNS DO SUDESTE DA FRANÇA EM CINCO FÓRUNS DIFERENTES. O OBJETIVO É COMPREENDER AS INTERAÇÕES ATRAVÉS DE UMA ABORDAGEM ETNOMETODOLÓGICA. COMO RESULTADOS, EU PUDE DESCREVER UMA ATIVIDADE REFLEXIVA ENTRE JURISTAS E LEIGOS. POR UM LADO, JURISTAS EXPLICAM O DIREITO UTILIZANDO A LINGUAGEM COMUM, ENQUANTO OS JURISDICIONADOS SE ESFORÇAM PARA COMPREEN DER AS NORMAS JURÍDICAS EM FUNC ĀO DE SUAS FINALIDADES PRÁTICAS. ESSA ATIVIDADE É POSSÍVEL GRAÇAS À CAPACIDADE DE CRIAR FERRAMENTAS COGNITIVAS USANDO ACCOUNTS CONTEXTUAIS. FINALMENTE, O TRABALHO NAS AUDIÊNCIAS JUDICIAIS PERMITE OBSERVAR COMO O DIREITO É REALIZADO ATRAVÉS DAS FERRAMENTAS COGNITIVAS QUE SÃO DESENVOLVIDAS NAS INTERAÇÕES ENTRE JURISTAS E JURISDICIONADOS.

\section{PALAVRAS-CHAVE}

JUSTICCA DE PROXIMIDADE; AUDIÊNCIA JUDICIAL; INTERAÇÕES ASSIMÉTRICAS; ETNOMETODOLOGIA.

\section{ABSTRACT}

THIS PAPER AIMS TO DESCRIBE THE ASYMMETRIC INTERACTIONS BETWEEN JURISTS AND LAY PEOPLE IN COURTROOMS. THE HEARINGS ARE AN INTERESTING ENVIRONMENT WHERE WE CAN OBSERVE THESE INTERACTIONS BETWEEN EXPERTS AND LAY PEOPLE. THE RESEARCH IS BASED ON OBSERVATION OF HEARINGS OF THE "JUGES DE PROXIMITÉ" IN COURTROOMS IN SOUTHERN FRANCE IN FIVE DIFFERENT COURTS. THE MAIN GOAL IS TO PROVIDE A THICK DESCRIPTION OF THESE INTERACTIONS FOR THE ANALYSIS IN AN ETHNOMETHODOLOGICAL POINT OF VIEW. AS A RESULT, I COULD DESCRIBE A REFLEXIVE ACTIVITY BETWEEN JURISTS AND LAY PEOPLE. IN ONE HAND, THE JURISTS EXPLAIN THE LAW IN ORDINARY LANGUAGE WHILE THE LAY PEOPLE MAKE A STRUGGLE TO UNDERSTAND THE LEGAL ASSESSMENTS FOR PRACTICAL PURPOSES. THIS ACTIVITY IS POSSIBLE DUE TO THE CAPACITY OF CREATING COGNITIVE TOOLS USING CONTEXTUAL ACCOUNTS. FINALLY, THE COURT HEARINGS WORK ALLOWS OBSERVING HOW THE LAW IS ACCOMPLISHED WITH THE COGNITIVE TOOLS WHICH ARE DEVELOPED BY THE INTERACTIONS OF LAWYERS AND LAY PEOPLE.

\section{KEYWORDS}

SMALL CLAIM COURT; JUdICIAL HEARINGS; ASSYMETRIC INTERACTIONS; ETHNOMETHODOLOGY.

Basta empurrar a porta de um tribunal (...) e observar.

DOMINIQUE SIMONNOT 


\section{INTRODUÇÃO}

Este texto deriva de minha pesquisa de doutorado sobre os Juízes de Proximidade (juges de proximité) na França (GERALDO, 2011). Durante o trabalho de campo, a escolha de ir assistir às audiências me pareceu evidente. Porém, ao reunir os dados recolhidos, eu me confrontei com um problema: como analisá-los?

Este artigo parte, então, dessa necessidade prática e teórica. Eu não compreendia bem as audiências quando as assistia. Enquanto jurista de formação e brasileiro, eu atribuía a incompreensão ora ao meu desconhecimento do sistema jurídico francês, ora aos obstáculos linguísticos.

No primeiro dia de observação, uma senhora sentou-se ao meu lado. A audiência já tinha começado. Eu estava particularmente ansioso, pois era a primeira vez que assistia a uma audiência como pesquisador. Ela se aproximou para me perguntar como deveria chamar o juiz: Senhor juiz ou Senhor presidente? Eu também não sabia muito bem. "Senhor juiz!", respondi. Estava participando de algo que eu mesmo não me dei conta. Após várias horas de observação e de reflexão, esse pequeno episódio corriqueiro e sem importância me pareceu significativo. Como nós podemos compreender as interações entre juristas e os jurisdicionados que não conhecem o direito? Como, apesar de tudo, eles interagem de maneira a satisfazer às necessidades de uns e de outros?

Este texto propõe uma análise etnometodológica desse encontro entre juristas e jurisdicionados. Primeiramente, é preciso reconhecer que o objeto de pesquisa, a perspectiva teórica e o campo escolhidos não são usuais à pesquisa sociológica que se realiza sobre o direito. A ordem dessas atividades ligadas à pesquisa também não me apareceu assim; fui a campo quando descobri a escassez de trabalhos empíricos sobre esse tema porém, os poucos que existem utilizam essa perspectiva teórica.

É por essa razão que a especificidade do campo de pesquisa é desenvolvida em sua importância. Em seguida, explicarei o que foi observado para que a conclusão seja reservada a uma análise mais aprofundada dos dados recolhidos.

\section{O CONTEXTO INSTITUCIONAL DA AUDiÊNCIA}

A cena judiciária é um lugar onde se pode desenvolver perspectivas etnográficas de pesquisa para compreender as práticas e as relações. O objetivo é demonstrar a maneira pela qual esse objeto de pesquisa pouco comum permite apreender as práticas dos profissionais do direito. Pretendo mostrar as razões que me conduziram a essa escolha metodológica para compreender o processo pelo qual se fabrica o direito - segundo Bruno Latour (2004) - em vez de partir dos resultados para compreender os processos pelos quais eles são produzidos.

O trabalho dos juristas sempre foi considerado um trabalho intelectual, no qual a retórica e a formalidade do discurso são os exercícios de base da profissão. Além disso, 
as formas de comunicação escrita também fazem parte dessa imagem de um profissional que deve conhecer o direito a fim de utilizá-lo de uma forma elegante e convincente.

Essa perspectiva do que os juristas fazem é utilizada como um dos pontos de apoio da análise sociológica proposta por Bourdieu (1986). Ele considera que há um conflito existente entre as "diferentes definições do trabalho jurídico como interpretação autorizada dos textos canônicos" (BOURDIEU, 1986, p. 6). O trabalho jurídico releva então uma disputa em torno da interpretação do direito. Todavia, isso não esclarece o que é esse trabalho interpretativo e os processos que os tornam objetivos; essa análise também nos ensina pouco sobre as relações com aqueles que o autor chama de profanos. Finalmente, essa abordagem do trabalho jurídico possui um sentido holístico, que engloba todas as atividades que concernem as profissões jurídicas, que não são a mesma coisa. Os advogados, os juízes, os escrivães e os oficiais de justiça, como todos aqueles das outras profissões ditas do direito, não possuem a mesma relação com o conhecimento do direito.

O trabalho dos juristas é então um tema inteiramente à parte que merece atenção, uma vez que o cotidiano de trabalho desses profissionais não é o mesmo. É preciso saber no que eles diferem. Obviamente, as funções não se exercem todas no mesmo lugar. Entretanto, se é verdade que eles se relacionam, eles o fazem nos fóruns.

Quando se trata de estudar atividades práticas como o trabalho, parte-se do seu resultado ou do processo pelo qual é produzido. O objetivo é poder avançar sobre essa noção de trabalho jurídico, considerando-o sobretudo como um processo em execução, mais do que um resultado pronto e acabado. Nos fóruns, podemos observar tal processo em ação.

As pesquisas sobre os tribunais tratam das inovações institucionais (ACKERMANN; BASTARD, 1993) e sobre os ritos judiciários (GARAPON, 1997); partindo desses trabalhos, percebi que a audiência é uma cena interessante para observar a realização do trabalho jurídico. Nelas pode-se assistir ao direito em ação. Segundo Garapon:

Para fazer justiça, é preciso falar, testemunhar, argumentar, provar, escutar e decidir. Para tudo isso é preciso primeiramente se encontrar em situação de julgar. O primeiro gesto da justiça não é nem intelectual, nem moral, mas arquitetural e simbólico: delimitar um espaço sensível que mantém à distância a indignação moral e a cólera publica, reservar um tempo para isto, estipular as regras do jogo, convencionar um objetivo e instituir os atores (GARAPON, 1997, p. 19).

Essa descrição permite compreender as atividades práticas, mas também o lugar onde elas se realizam. O momento da audiência é assim uma fonte de pesquisa interessante para observar o trabalho dos profissionais do direito, porque se pode igualmente ver como esse trabalho é realizado com os leigos. 
Recentemente realizou-se uma série de trabalhos sobre audiências. O trabalho do juiz é central para alguém que as assiste, ainda que ele não seja o único a trabalhar na sala; tendo por objetivo seguir essas pistas de pesquisa, procurei entender o trabalho do juiz nas audiências. Em uma revisão bibliográfica sobre esse tema, Angèle Christin (2006) se questiona: o que nós sabemos sobre a profissão de juiz? Como analisar sociologicamente o trabalho dos juízes?

Ao se observar a paisagem judiciária francesa no que diz respeito aos juízes, vemos que esse personagem que encarna o papel do jurista pertence a um corpo bem estudado (BANCAUD, 1993; BOIGEOL, 2010; CAM, 1978; GARAPON; SALAS, 2006; ISRAËL, 2005; MICHEL; WILLEMEZ, 2007; VAUCHEZ, 2004; ZAPPULLI, 2009), mas não homogêneo. Ao se aproximar das abordagens, as diferenças saltam aos olhos. As recentes reformas da justiça em França (VAUCHEZ et al., 2007) criaram um novo tipo de juiz: o juiz de proximidade. Para além das controvérsias em relação ao estatuto jurídico desse novo tipo de magistrado, constata-se de fato que todos esses juízes possuem uma formação jurídica ${ }^{1}$ (PÉLICAND, 2009).

A função de juízes de proximidade foi criada em 2004 para julgar os pequenos casos da vida cotidiana. A competência legal no âmbito cível abarca as causas de até 4 mil euros, enquanto que, em matéria criminal, esses juízes têm a competência para julgar os casos de menor potencial ofensivo. A lei estabelece como critério para o recrutamento, em todos os casos, a experiência dos candidatos na área do direito, ou seja, eles são submetidos ao código da magistratura. No entanto, podem manter uma outra atividade principal. Esses juízes têm um mandato de sete anos não renováveis, sendo remunerados por hora trabalhada. O recrutamento é feito pelo Ministério da Justiça com a assistência da Corte de Apelação e do Conselho Superior da Magistratura. Por fim, eles não são autorizados a portar a toga, considerada o símbolo do poder de julgar; no seu lugar, determinou-se o uso de uma medalha dourada suspensa por uma fita azul.

A sala de audiência é o lugar da pesquisa, porém como nos adverte Cliford Geertz, “o local de pesquisa não é o objeto do pesquisa” (GEERTZ, 1973, p. 22). O objeto não é o ambiente de uma sala. O que me interessa particularmente é saber o que se deve visar na sala de audiência para analisar sociologicamente o trabalho realizado.

Apesar da referência à obra de Garapon (1997), a análise não seguirá sua metodologia, pois esta se utiliza de uma perspectiva estática dos elementos que compõem a cena judiciária. Outros trabalhos sobre as interações entre os profissionais relevam principalmente o caráter dinâmico de uma audiência, como os escritos de Dupret (2001, 2010, 2011), que utiliza uma abordagem praxeológica e inspira essa análise, versando a respeito do trabalho de diferentes profissionais que atuam nos processos judiciais no Egito. Nessa linha também estão as pesquisas de Atkinson e Drew (1979) sobre o trabalho profissional e as interações em audiências estadunidenses, além de outro trabalho de Drew (1993) sobre a estratégia de desqualificação dos depoimentos 
das testemunhas no júri norte-americano, bem como a pesquisa de Lynch (1998) sobre o trabalho do juiz durante as audiências canadenses, a pesquisa de González Martínez (2005), que realizou uma análise de conversação "a partir do conjunto de gravações audiovisuais efetuadas por Raymond Depardon no Palácio de Justiça de Paris para o seu documentário Délits flagrants (1994)" (GONZÁLEZ MARTÍNEZ, 2005, p. 212) e o trabalho de Israël (1999) sobre o trabalho do juiz de menores realizado a partir de observações para a elaboração de uma explicação externalista "em termos dramatúrgicos propostos por Erving Goffman”(ISRAËL, 1999, p. 394). Eles focalizam as interações como um processo de realização da Justiça. No Brasil, os trabalhos realizados sobre audiências buscam compreender os processos de administração de conflitos como as audiências dos juizados especiais criminais na baixada fluminense (AMORIM; KANT DE LIMA; BAUMANN BURGOS, 2003); há também diferentes trabalhos acerca dos julgamentos no tribunal do júri no Brasil (FERRAZ DE ALMEIDA, 2013; KANT DE LIMA, 2009; SCHRITZMEYER, 2007); a pesquisa sobre as sensibilidades jurídicas nas audiências no Brasil e na Argentina (EILBAUM, 2013) e as formas de administração de conflitos nas audiências nos juizados de violência doméstica e familiar contra a mulher (ALIMENA; AZEVEDO, 2011).

No início da pesquisa as observações eram difíceis de realizar, pois eu não sabia muito bem como orientar minha observação. Este trabalho se inspira nessa perspectiva de pesquisa para compreender as interações e suas consequências. Durante a pesquisa sobre os juízes de proximidade, rapidamente me dei conta que não havia muitas audiências para assistir, pois eles são em menor número e, assim, havia poucas audiências. Por isso, decidi ir a outros tribunais assim que a pesquisa de campo começou.

Este trabalho foi realizado com os dados dessa pesquisa, bem como das entrevistas com os juízes de proximidade e profissionais. Uso as observações realizadas em cinco tribunais de primeiro grau do sudeste da França (em Montpellier, em Sète, em Nîmes, em Bèziers e em Avignon), totalizando mais de 60 horas de observação em vinte audiências. Esses tribunais são de tamanho variável do ponto de vista de sua atividade judiciária e de seus efetivos, o que produz efeitos sobre as relações que se estabelecem nos tribunais e nas práticas em cada um deles.

Essa pesquisa de campo multissituada (STARR; GOODALE, 2002) me permitiu recolher os dados em diferentes lugares a fim de poder compará-los para compreender suas diferenças, nos moldes das pesquisas antropológicas (KANT DE LIMA, 2009). Assim, pude me interrogar a partir de vários campos que são similares e, ao mesmo tempo, distintos.

As observações foram realizadas a partir de duas perspectivas diferentes: eu me sentei nos bancos que são reservados aos jurisdicionados, onde pude observar melhor as interações entre os jurisdicionados e os advogados, e também ao lado do juiz, onde pude considerar as interações entre ele e os jurisdicionados. As duas perspectivas chamaram minha atenção para dois fenômenos diferentes que descrevi progressivamente. 
Refletindo sobre meu trabalho, profundamente descritivo, me confrontei com os trabalhos etnográficos graças à necessidade de compreender as descrições que fazia. A abordagem que mais me interessou foi a etnometodologia, pois se trata de "uma pesquisa empírica de métodos que os indivíduos utilizam para dar sentido e ao mesmo tempo realizar suas ações de todos os dias: comunicar, tomar decisões, raciocinar" (COULON, 1993, p. 23). Eu pretendo ao mesmo tempo escapar da dicotomia internalista/externalista da análise do direito buscando compreender como juristas e leigos dão sentido ao direito no curso de suas interações. Além disso, busco compreender melhor as interações assimétricas entre juristas e leigos, e o porquê de os juristas possuírem a expertise sobre o direito e serem investidos de prerrogativas. Considero assimétricas aquelas interações nas quais tais prerrogativas e obrigações na interação não são as mesmas, tal como descreve Goffman (1982).

Não pretendo realizar uma interpretação do direito e de seu sentido em si, ao modo dos juristas. Contudo, não pretendo também ignorar que os juristas dão sentido às suas próprias atividades e ao direito. O objetivo é elaborar uma reflexão a partir de um material contextualizado sobre a seguinte questão: como as relações com os leigos permitem compreender o trabalho dos juristas no curso de uma audiência?

\section{A AudiênCIA EM AÇÃo}

O trabalho em audiência é uma parte específica do trabalho dos juristas; na audiência, podem encontrar outros práticos do direito e os jurisdicionados que não conhecem o direito, ou o conhecem apenas vagamente. Esse momento é particular, pois serve para realizar uma tarefa específica do procedimento de instrução do processo e de julgamento. Essas atividades respeitam regras jurídicas precisas, mas a aplicação é dinâmica e engendra um exercício intelectual mais complicado do que aparenta. Segundo a expressão de um autor (GEERTZ, 1973, p. 3), proponho realizar uma descrição densa desse lugar da pesquisa e dos encontros de práticos do direito com os jurisdicionados.

As audiências da jurisdição de proximidade em regra são públicas, o que permite observá-las ao lado dos jurisdicionados e dos advogados. Elas podem durar de 30 minutos a 4 horas, segundo a quantidade de processos que são arrolados para audiência e a sua natureza, pois existem as audiências para julgar os processos cíveis e aquelas para julgar os processos criminais. Usualmente, as audiências brasileiras se destinam a um único processo, enquanto vários processos são instruídos e julgados nas audiências do judiciário francês.

Os elementos de uma sala de audiência são sempre os mesmos, o que não quer dizer que eles sejam iguais, pois variam em relação aos recursos do tribunal. Há a mesa onde se sentam o juiz, o escrevente, o representante do Ministério Público e, nas audiências criminais, o Oficial de Justiça. Na frente, há a barra, supostamente até 
onde as pessoas podem ir. Há uma parte reservada aos advogados, e outra para o público. A seguir, o croqui da sala de audiência do Fórum de Montpellier:

\section{Figura 1 - Sala de Audiência do Fórum de Montpellier}

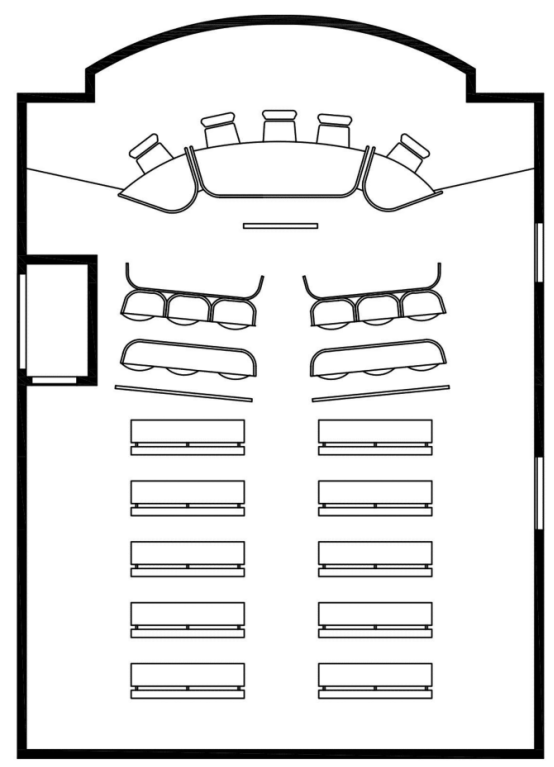

Além disso, há os advogados e os jurisdicionados. Para todas as causas em primeiro grau, no qual a jurisdição de proximidade faz parte, a assistência de advogados não é obrigatória. Apesar disso, há uma grande presença de advogados durante as audiências. Estes permanecem sempre próximos à barra e à mesa do juiz no espaço que lhes é reservado na geografia da sala. Finalmente, há os jurisdicionados, sempre numerosos nessas audiências. Eles vêm com ou sem advogado; sozinhos ou acompanhados por alguém conhecido. Chegam todos juntos na mesma hora inscrita nas citações que eles trazem consigo. A audiência começa em princípio com todos os interessados; isso estrutura institucionalmente a publicidade das audiências judiciárias. Não há a necessidade de pedir a autorização ao juiz ou aos funcionários para assisti-las. As observações me permitiram constatar que a maioria não compreende muito o que está para acontecer nos instantes que se seguirão. O exercício inicial é esperar. Enquanto todos esperam, observam o desenrolar do rito.

O ritual é chamado de procedimento de instrução pelos membros. O trabalho consiste a priori em recolher os documentos que fundamentam a sustentação oral das partes 
para que o juiz que preside a audiência possa ter elementos para julgar. Todavia, o procedimento é diferente segundo a natureza da audiência. Em matéria cível, a audiência possui duas etapas: a primeira é a chamada de causas ("l'appel des causes"), na qual as partes são chamadas a se apresentar para informar se o processo está em condições de ser sustentado, ou seja, se as partes comunicaram as petições e as provas antes da audiência para que se respeite o princípio do contraditório. Assim, o processo pode: ir para julgamento; ter um acordo homologado pelo juiz; ser julgado em audiência, quando se trata de decisões que põem fim ao processo sem julgamento do mérito; ser adiado para que seja apresentado em outra audiência a fim de que as partes regularizem a troca de documentos; ou ser mantido na pauta para instrução. Quando todos são chamados, inicia-se a segunda etapa, a sustentação oral ("les plaidoiries"). O juiz que preside a audiência passa a palavra ao autor da ação para que ele realize o pedido ou, simplesmente, para que entregue sua petição por escrito. Em seguida, passa a palavra ao réu para que ele apresente sua defesa oralmente ou por escrito.

O escrevente é o garante do procedimento; na prática, isso significa que ele segue o rol da audiência para certificar os atos e atestar se as pessoas estão presentes ou ausentes. Todo o necessário para preparar um processo é igualmente realizado pelos escreventes. Os julgamentos podem ser realizados logo após a sustentação ou em outro momento, ou seja, o processo será analisado pelo juiz que proferirá o seu julgamento posteriormente. Esse é um aspecto interessante do judiciário francês, pois o juiz deve se preocupar sobretudo com as questões de fundo do processo, compartilhando a responsabilidade pelo andamento do processo com os funcionários. As sentenças judiciais contêm assim as assinaturas do juiz e do greffier-en-chef, o chefe da secretaria.

Em matéria criminal, o procedimento não é o mesmo. Os processos são chamados pelo Oficial de Justiça, que os transmite ao juiz; o réu e as vítimas que podem realizar o pedido de reparação nos autos devem se apresentar em audiência. Nessa ocasião, é feita uma análise da regularidade da citação. Em caso de sua nulidade, o juiz pergunta ao réu se ele aceita ser julgado assim mesmo, já que compareceu espontaneamente. Caso contrário, é necessária outra citação para regularização do processo. Em seguida, o juiz pergunta se o réu reconhece os fatos pelos quais é julgado depois de ler o boletim de ocorrência da polícia que se encontra no processo. Se ele os reconhece, o presidente em seguida passa a palavra ao representante do Ministério Público. Do contrário, o réu expõe sua versão dos fatos (ou seu advogado). Após a palavra é dada à vítima (ou ao seu advogado) para expor seu pedido de indenização, cuja legitimidade, assim como o fundo (ou seja, o montante da indenização), o juiz apreciará. Em seguida, é a vez do representante do Ministério Público, que expõe suas motivações para fazer os seus pedidos. A palavra volta ao réu para a réplica às requisições do representante do Ministério Público e da vítima. A conclusão é o julgamento. Os juízes têm diferentes métodos para julgar. Os julgamentos podem ser dados logo após as sustentações orais, ou, se não, o juiz pode deixar para julgar ao 
fim da audiência, depois de suspendê-la para julgar em segredo. Além disso, ele ainda pode deixar para julgar mais tarde e entregar o julgamento outro dia. Ou, enfim, adotar todos esses métodos durante uma audiência. O papel do escrevente não é o mesmo, porque ele deve tomar notas de audiência.

A rotina de trabalho é construída pela repetição desses atos a cada vez que um processo é chamado. Essa rotina pode ser entendida de maneira abstrata, enquanto ritual ideal típico. Desse ponto de vista, todas as audiências são iguais. Contudo, considero-as uma rotina de trabalho, na qual os membros desenvolvem tarefas diversas. Esse é um momento dinâmico, onde várias pessoas, que não são sempre as mesmas, interagem, o que permite afirmar que, apesar do mesmo rito, as audiências são sempre diferentes.

A participação dos jurisdicionados é talvez o que torna esses momentos interessantes de observar. A interação dos advogados e dos juízes com os jurisdicionados transforma essa rotina de trabalho, pois ela não é previamente conhecida por todos. As incompreensões e os mal-entendidos aparecem, porque a linguagem do direito não é dominada pelos jurisdicionados. O trabalho é realizado com todos esses membros, apesar de todos esses problemas.

A finalidade deste trabalho é compreender como essa interação ocorre. A presença de pessoas que não conhecem nem o procedimento e nem o direito não as impede de interagir e de se compreenderem reciprocamente. Este trabalho utiliza as ferramentas teóricas da etnometodologia (GARFINKEL, 1967) a fim de explicar como a interação assimétrica é possível. Dois conceitos serão utilizados para formular as hipóteses: membros e accounts. Cada um serve para compreender as interações em contextos precisos. Por membros, considera-se as pessoas que compartilham a mesma compreensão e possuem uma mesma compreensão do senso comum de um determinado contexto (GARFINKEL, 1967, p. 40); accounts são fatos sociais "descritíveis, inteligíveis, reportáveis e analisáveis” (COULON, 1993, p. 39). Os membros se identificam como tais em um contexto quando compartilham os mesmos accounts; em outras palavras, são pessoas que podem se compreender reciprocamente sem que a interação seja rompida para fornecer explicações sobre o sentido que as coisas, pessoas e situações têm para eles.

Pretendo mostrar como se pode compreender as interações a partir dessas ferramentas teóricas. O exercício não é fácil, porque será preciso descrever as cenas e os instantes de audiências para compreender como o trabalho da audiência é conduzido. É a partir da descrição minuciosa da interação dos membros que mostrarei em que medida ela é dinâmica.

Essa abordagem é apenas uma maneira de compreender esses fenômenos. Tratase de um programa metodológico para compreender a interação e os fatos comuns da vida cotidiana. O interesse é utilizar esses instrumentos para realizar uma reflexão microssociológica sobre as interações de experts em direito com os jurisdicionados que não dominam a técnica jurídica. 
As observações foram realizadas em salas de audiências graças à publicidade dos debates e do seu tamanho, que comporta um grande público. As audiências dos juízes de proximidade são menos frequentes que as audiências dos magistrados profissionais, o que me obrigou a adotar uma estratégia de uma pesquisa multissituada em vários tribunais de primeiro grau das jurisdições da Corte de Apelação de Montpellier e de Nîmes. Por uma questão ética da pesquisa empírica, não farei nenhuma referência ao fórum, nem a dados que possam identificar as pessoas envolvidas. O objetivo não é descobrir o sentido oculto das coisas, ao contrário: é mostrar o sentido dado pelas próprias pessoas às situações em contextos específicos. Como Garfinkel diz mais claramente, é necessário "prestar às atividades mais comuns do cotidiano a atenção usualmente dada aos eventos extraordinários, buscar apreendê-las como fenômenos dignos de atenção por si só” (GARFINKEL, 1967, p. 1).

É importante lembrar que os fenômenos observados são generalizáveis para todos os juízes de proximidade em toda a França. A atenção é prestada aos fenômenos, que são repetitíveis enquanto atividades rotineiras do trabalho cotidiano em um fórum. $\mathrm{O}$ interesse é fazer uma análise das estratégias desenvolvidas pelas pessoas para interagir nesse contexto.

As cenas foram escolhidas para mostrar os fenômenos que apenas são perceptíveis depois de muito tempo de observação. A exposição dos dados busca demonstrar os fenômenos analisados, devido à impossibilidade de descrever tudo. Nos quadros a seguir, cada descrição será seguida dos diálogos, que serão explicados. Após várias horas de observação, eu mesmo adquiri a qualidade de membro competente, o que quer dizer que eu era capaz de compreender o sentido das ações entre uns e outros. A segunda coluna é o resultado de um trabalho de intérprete que eu realizei enquanto membro competente, ou seja, dou instruções a fim que uma pessoa ausente possa compreender o sentido daquilo que os membros estavam fazendo.

Estava em uma audiência cível que havia começado às 14 horas, e o juiz chamava os processos. Às 14h57, um senhor de meia idade se aproxima da barra: ele sabia que deveria fazê-lo, pois todos que foram chamados o fizeram; quando o seu nome foi chamado, não hesitou em ir até lá. Como a maioria dos jurisdicionados, ele tinha papéis à mão. Ele era o autor, e a parte contrária estava ausente:

\section{Juiz de}

proximidade: - O Senhor quer sustentar

o pedido ou apenas deixar os documentos?

Eu quero saber se os debates serão abertos para o exercício do contraditório. O processo nesse caso será retido para que o senhor possa sustentar o seu pedido, ou seja, explicar os fatos e as razões jurídicas que justifiquem o seu interesse de 
reclamar em Justiça e os fundamentos jurídicos do seu pedido.

Mas eu gostaria de saber também se o senhor quer renunciar ao seu direito de sustentar para juntar ao processo os documentos que justifiquem o seu interesse e sua causa a fim que o processo seja julgado. Pois eu creio que o senhor tenha em mãos vários documentos que eu suponho que são relacionados ao processo.

$$
\begin{aligned}
& \text { - Eu me explico: } \\
& \text { o Senhor quer me dar } \\
& \text { explicações ou apenas saber } \\
& \text { a data do julgamento? Como eu percebo que o senhor }
\end{aligned}
$$$$
\text { aparentemente não entendeu minha }
$$

pergunta e vejo que estes papéis talvez não sejam pertinentes, gostaria de saber se o senhor quer abrir os debates para sustentar seu pedido.

Caso contrário, quero saber se o senhor quer apenas saber o dia em que o julgamento será dado, renunciando assim o seu direito de sustentar o pedido. Nesse caso, o processo será decidido em uma outra data, e o julgamento será enviado para o senhor.

$$
\text { Jurisdicionado: — Eu quero falar! }
$$

Após a explicação sintética, que tornou as opções mais claras, eu decidi falar, ou seja, eu quero dar explicações que me parecem pertinentes.

\section{Juiz de}

proximidade: - Então espere um pouco. Já que o senhor decidiu sustentar seu pedido, eu irei chamar o processo na segunda fase da audiência para ouvir suas explicações. Eu peço ao senhor o favor de permanecer na sala e esperar ao final desta fase para que eu possa ouvi-lo exercendo seu direito.

Aquele senhor entendeu bem, pois voltou para se sentar e esperar sua vez de ser chamando novamente. Essa interação durou mais ou menos quatro minutos. A pilha de processos anunciava a duração da audiência, que terminou às 17 horas. Essa pequena cena do cotidiano dos fóruns nos mostra como os accounts se constroem, pois a possibilidade de ver o que acontece com os outros permite aos jurisdicionados construir um conhecimento contextual a partir da observação. O reflexo do senhor que foi até a barra quando foi chamado e depois a deixou mostram movimentos de rotina durante uma audiência. Certamente, a linguagem comum e a técnica se misturam. Fazendo 
isso, o juiz utiliza atalhos para explicar o procedimento ao qual as pessoas começam a se familiarizar. O jurisdicionado sabe que quando for chamado novamente suas explicações serão pedidas. O tempo de espera lhe permitirá continuar a observar as interações e aprender o que poderá fazer.

Durante esse tempo de espera, as interações também ocorreram entre as outras pessoas que estão na sala. Os advogados têm o hábito de conversar entre eles e com os jurisdicionados. Nesse momento, pude identificar alguns indícios que mostram como a audiência é dinâmica. Os jurisdicionados, que não dominam a situação, fazem esforços objetivos para aprenderem a se comportar, ainda que esse conhecimento não seja transmitido de uma maneira sistemática e pedagógica.

Assistia a uma audiência civil quando pude observar um senhor mais velho ao meu lado com uma pasta preta cheia de papéis e um livro grosso azul com o título em branco. Às vezes, ele o folheava para ler, mas o fazia rapidamente sem seguir uma ordem precisa, porque o folheava indo do início diretamente ao fim. Eu entendi que se tratava de um livro para ajudá-lo a entender os seus direitos. O título era Proprietários e locatários: quem paga o quê?, com o subtítulo Perguntas e respostas. Ele lia a seção de perguntas e respostas e depois lia a seção de modelos de petição, nos quais bastava preencher as coordenadas do autor e do réu, pois as motivações jurídicas já estavam todas indicadas.

Em outra audiência cível, ouvi uma conversa entre dois jurisdicionados atrás de mim. A audiência já tinha começado. Um processo foi chamado, e em seguida um advogado se apresentou pelo seu cliente que não estava presente. A parte adversária - um jurisdicionado - se aproximou da barra. O advogado informou que ele não recebeu os documentos, pois estes foram enviados ao seu cliente, e não a ele. O jurisdicionado queria explicar uma coisa, o que o juiz não autorizou, porque não se estava ainda na segunda fase da audiência (a sustentação oral). Essa justificativa ainda não havia sido enunciada durante a audiência, uma vez que ela começou às $9 \mathrm{~h}$ e ainda eram 9h30; assim, as pessoas puderam compreender como era o rito. O juiz decidiu marcar outra data de audiência para o processo, pois o procedimento precisava ser regularizado. Ele explicou ao jurisdicionado que quando alguém contrata um advogado, os documentos devem ser encaminhados para o mesmo. O jurisdicionado, que não fora autorizado a falar, ainda insistiu nervoso e trêmulo quando dirigiu a palavra ao juiz. Durante esse episódio, dois jurisdicionados - um homem e uma mulher comentavam o que viram:

Mulher: - Era preciso enviar os documentos?!

Ao observar o episódio que acabou de acontecer, eu entendi que os documentos que pretendo mostrar ao juiz deveriam ter sido enviados ao meu 
adversário o que não acontece porque o juiz quer, mas porque faz parte das regras do procedimento.

Eu estou surpresa.

É realmente isso que eu entendi?

Homem: - Sim, era.

exatamente assim que eles fazem.
Sim [respondeu sorrindo], pois do que eu conheço dos tribunais, é
Mulher: —Eu não sabia.

dimento jurídico. Sobretudo porque sinto que eu não estou preparada, pois não enviei os documentos para a parte adversária.
Depois de assistir a audiência confesso que não conhecia o proce-

A possibilidade de assistir a audiência permite às pessoas construir um conhecimento pragmático do contexto; eles se tornam membros, pois estabelecem meios comuns para se compreender reciprocamente. Os jurisdicionados utilizam o que aprendem pela observação para interagir com o juiz.

Eu me dei conta dessas práticas quando estava assistindo a uma audiência ao lado do juiz. Nos estávamos na fase das sustentações - a segunda fase da audiência -, os processos em que advogados são chamados inicialmente. É comum chamar o juiz de Senhor Presidente, embora seja preciso saber que o juiz, além de julgar, preside as audiências, o que explica a grande maioria das pessoas referirem-se a ele como Senhor Juiz. Nesse dia, vários advogados tinham sido ouvidos, e em seguida os outros processos foram chamados. Depois de ser chamada, uma senhora se aproximou sem saber muito que fazer, dirigindo-se ao juiz chamando-o de Senhor Presidente. Eu me surpreendi, pois pude observar que apenas poucos o faziam. A forma de tratamento foi sem dúvida uma coisa que tanto ela quanto eu aprendemos durante a audiência.

Além desses conhecimentos, que parecem triviais, os jurisdicionados tentam compreender como o juiz decidirá. As audiências criminais são melhores para observar isso, pois o julgamento é muitas vezes dado logo após a sustentação oral de ambas as partes. Eu estava ao lado do juiz nesse dia, e a audiência tinha começado às $14 \mathrm{~h}$. Havia muitos processos de excesso de velocidade nos quais os réus tinham sido fotografados por um instrumento de medição da velocidade nas estradas. As constatações das infrações foram enviadas ao representante do Ministério Público para a requisição das multas, que o réu pode pagar ou contestar em juízo; a constatação é uma prova realizada pelo Estado e difícil de se contestar, pois são os técnicos da polícia 
que se encarregam das questões sobre a máquina. Ela é praticamente irrefutável: as nulidades de forma são raras e a regularidade da instalação da máquina é sempre atestada por um laudo técnico. O representante do Ministério Público explicava suas razões aos jurisdicionados antes de fazer suas requisições. Outro caso foi chamado, e uma jovem se aproximou. Após a leitura do processo, o juiz disse:

\section{Juiz de}

proximidade: - Cabe a você trazer

a prova.

Eu digo que para contestar os fatos que são imputados a você por uma requisição fundada em provas válidas demonstradas pelo representante do Ministério Público, é preciso nos mostrar elementos juridicamente válidos que sejam impeditivos, modificativos ou extintivos do exercício do direito de sancionar do Estado.

Jurisdicionado: - Sim, eu sei. Eu ouvi há pouco, mas como eu posso fazer?

Sim, eu entendi, pois estava na sala quando o senhor exigiu a produção de provas de uma outra pessoa para que pudesse ter uma decisão favorável, apesar de não conhecer muito bem o direito e os meios de produzir tais provas para demonstrar que eu tenho razão em pedir um julgamento favorável.

O representante do Ministério Público explicou que era preciso uma prova contraditória capaz de demonstrar que a constatação feita pela máquina estava errada. Em seguida, requereu uma multa de 68 euros contra a ré.

\footnotetext{
Juiz de

proximidade: - Ou eu confirmo, ou eu absolvo. Eu não tenho margem de manobra.
}

Depois de ouvir as requisições do representante do Ministério Público, eu indico que sou obrigado a julgar de acordo com o texto da lei que somente me autoriza a julgar diferentemente das requisições do Ministério Público se você me trouxer provas que demonstrem o contrário.

Por esta razão, eu sou obrigado a confirmar as requisições te condenando, ou a te absolver declarando sua inocência. A lei não me permite fazer outra coisa. 
Jurisdicionado: —É uma pena para

$o$ cidadão.

favorável [respondeu sorrindo].

$\mathrm{Eu}$ compreendo as razões pelas quais eu não tenho um julgamento

Eu considero, porém, que isso não é benéfico para as pessoas que, como eu, não possuem nenhum meio de controle sobre o sistema de produção de provas do Estado. Pois para compreendê-lo é preciso ter um conhecimento que alguém como eu não possui.

Enfim, o juiz confirmou a requisição do Ministério Público; o fato de ter observado outro caso permitiu à jovem compreender que não tinha argumentos suficientes para sustentar o seu pedido. A linguagem muda para que as regras de direito sejam compreensíveis pelas pessoas, que conseguem se entender graças a um esforço recíproco de explicar os termos técnicos em uma linguagem comum. Do outro lado da barra, o jurisdicionado se esforça igualmente para entender as regras de funcionamento que se impõem às pessoas a fim de assimilar o que pode acontecer durante a interação.

O sentido oscila entre os usos técnico e comum da linguagem. É interessante perceber como as explicações são breves. Elas são atalhos criados no contexto para facilitar a interação. O que é do vernáculo permite às pessoas associarem o sentido compartilhado no contexto para tornar a interação compreensível. O sentido é estabelecido no curso das interações entre as pessoas, e o direito adquire um sentido voltado para o contexto. Desse modo, o sentido aparece como descobertas para as pessoas que o reelaboram em relação às finalidades do contexto em que estão (LIBERMAN, 1999). O que é técnico permanece técnico, mas as situações servem de exemplos observáveis pelas pessoas, que assim podem compreender o que acontece. A formação dos accounts é o resultado desse exercício interativo de se remeter às experiências compartilhadas. Assim, o estatuto de membro adquire seu sentido, pois as pessoas se tornam membros na medida em que compreendem o que acontece na sala de audiência; o sentido contextual explícito na interação é acessível a todos.

Um outro exemplo de construção em um sentido moral, para se opor o que é próprio da técnica jurídica. Eu estava em uma audiência criminal que tinha começado às 9h30. Eram 10h05. Havia umas vinte pessoas na sala. O oficial de justiça chamou um dos casos arrolados: havia o réu, um jovem forte e a vítima, que era uma mulher magra e, aparentemente, fraca. Tratava-se de um caso de violência leve. Ele havia dado um tapa na mulher. O juiz leu o boletim de ocorrência, e em seguida algumas explicações foram dadas pelo réu. O juiz o interrompeu: "Não se bate em mulher. É preciso saber que não se bate em mulher". Quando a segunda parte da frase foi dita, as pessoas presentes sacudiam as cabeças, mostrando sua concordância com a afirmação do juiz. A frase foi sonora. Parecia que todos na sala estavam de acordo. Os fatos estavam 
constituídos. O juiz confirmou as requisições do representante do Ministério Público e deferiu o pedido de indenização por danos morais à vítima. Anunciando o julgamento, ele repetiu as frases que eram a justificativa e a decisão ao mesmo tempo. Nesse caso, os princípios morais serviram de ponte para compreender a justificação jurídica. A análise dos elementos da personalidade para julgar o réu sempre é importante em um processo criminal. O fato de o juiz ter lido o atestado médico em público e de ser evidente para todos na sala que o réu era muito mais forte permitiu que o magistrado expusesse essa frase, que resumia o conteúdo da sua decisão e o acordo dos jurisdicionados que lá estavam.

A regra jurídica anunciada em uma linguagem comum traz com ela um sentido moral. Como disse o juiz de proximidade:

\section{Juiz de}

proximidade: - Não se bate em mulher. Considerando que a lei nos proíbe de agredir quem quer que seja e que neste caso não há nenhuma justificativa para a exclusão da culpabilidade penal;

Visto que os elementos constantes no processo demonstram que você realmente cometeu os atos que lhe são imputados e que você é muito mais forte que a vítima que aparentemente não possui meios de defesa;

Então, você não tinha o direito de

agredi-la.

$$
\begin{aligned}
& \text { _É preciso saber que } \\
& \text { não se bate em mulher. } \quad \text { Depois de expor esse raciocínio que }
\end{aligned}
$$$$
\text { me parece convincente para todos }
$$

os outros na sala, eu afirmo que você não tinha o direito de agredir esta pessoa.

Durante as diferentes etapas da audiência, as interações em ação permitem que as pessoas compreendam os diálogos entre os profissionais e os leigos; em momento algum elas se interrompem por causa dos mal-entendidos. Isso é uma parte do trabalho da audiência, e através da observação atenta às interações, eu pude constatar dois fenômenos: a aprendizagem dos jurisdicionados e o uso da linguagem comum pelos profissionais para explicar as regras jurídicas.

\section{O SENTIDO DAS INTERAÇÕES NA AUDIÊNCIA}

Após expor os dados empíricos da pesquisa de campo, cujo objetivo era mostrar as 
interações entre as pessoas, o interesse agora é o resultado prático dessas interações. O conceito de membro, como explica Garfinkel e Sacks, significa:

A noção de "membro" é o cerne da questão. Não empregamos o termo "membro" com referência a uma pessoa. Refere-se, sim, ao domínio da linguagem natural, o qual entendemos da seguinte maneira.

Observamos que pessoas, na medida em que estão falando uma linguagem natural, de alguma forma estão envolvidas na produção objetiva e exposição objetiva de conhecimento de senso comum de atividades cotidianas como fenômenos observáveis e relatáveis. Perguntamos: o que faz com que a linguagem natural permita aos falantes e ouvintes ouvirem, e de outra forma, testemunharem a produção e exibição objetivas de conhecimento de senso comum, e de circunstâncias práticas, ações práticas, bem como de raciocínio sociológico prático? O que faz com que a linguagem natural torne esses fenômenos observáveis-relatáveis, ou seja, fenômenos relat-áveis? ${ }^{2}$ Para falantes e ouvintes, as práticas da linguagem natural de alguma forma exibem esses fenômenos nas particularidades da fala, e que esses fenômenos são exibidos é por si só, e, por isso, exibível em descrições adicionais, comentários, perguntas e outras formas de narrar. (GARFINKEL; SACKS, 2012, p. 227)

Como compreender que o resultado de uma interação é o compartilhamento de um sentido comum? Para responder a essa questão, desenvolverei dois conceitos concernentes aos diferentes fenômenos. Começarei pelo o que eu chamo de aprendizagem, que na realidade é a construção de uma forma de conhecimento. Em seguida, demonstrarei a relação com os esforços de interpretação das regras técnicas como regras morais, o que na realidade é o uso da linguagem comum para facilitar a compreensão das questões práticas envolvendo o trabalho dos profissionais.

A interação em uma sala de audiência entre profissionais e leigos é assimétrica (DREW; HERITAGE, 1993), o que é inevitável quando um jurisdicionado se apresenta só, sem nenhum advogado para representá-lo. Essa interação certamente não faz parte de seu cotidiano, nem de sua rotina. Além disso, o procedimento de citação a uma audiência obriga que os interessados sejam citados pelos menos 10 dias antes da audiência; isso quer dizer que as pessoas têm um certo tempo para se preparar. Tal preparação exige um esforço de compreensão do que pode acontecer, e esse esforço não acaba com a chegada na audiência. Os pequenos indícios da vida cotidiana que eu pude observar - como as pessoas que levam livros explicando sobre os direitos e, ainda, as manifestações verbais daquelas que afirmam ter ouvido os debates para compreender melhor o rito, por exemplo - me permitem refletir sobre o esforço cognitivo feito pelos jurisdicionados. 
A audiência é assim uma cerimônia onde certas regras são previamente estabelecidas. Assim que os leigos começam a interagir nesse contexto, acontece o processo cognitivo de construção de uma compreensão que os permitem se familiarizar com essa situação para todas as finalidades práticas. Segundo Garfinkel, os elementos do contexto passam a funcionar como "questões levadas em consideração para todos os fins práticos”3 (GARFINKEL, 1967, p. 34). Isso significa que os jurisdicionados começam a se esforçar antes e continuam a fazer esse esforço durante o momento da interação, a fim de poder compreender as consequências práticas que lhes interessam.

$\mathrm{Na}$ audiência, a familiarização cognitiva se objetiva através das estratégias utilizadas pelas pessoas com a finalidade de compartilhar o sentido das ações com os experts. A qualidade de membro é adquirida no momento em que o jurisdicionado pode compreender o que acontece; os mal-entendidos tornam objetiva essa vontade de se entender com os experts. As explicações dadas por eles visam a satisfazer essa necessidade manifestada nas interações para atender, de um lado, a necessidade do jurisdicionado de saber o que acontece, pois seus interesses estão em jogo; e, de outro, os profissionais, pois eles necessitam saber o que os jurisdicionados querem para poder realizar o trabalho.

No entanto, as explicações não são a única maneira de ter acesso a um conhecimento tácito dos profissionais. As observações dos eventos e das situações na audiência são igualmente importantes como fontes de aprendizado do rito e do saber técnico jurídico. Essa atividade cognitiva é um trabalho de interpretação (GARFINKEL, 1967, p. 25) da situação na medida em que os significados são comunicados por meio da linguagem comum. Os meios utilizados pelos jurisdicionados servem para estabelecer os pontos comuns da cognição para lhes permitir compreender reciprocamente o que acontece na interação.

Dessa forma, os acordos sobre os sentidos são sempre contextuais, precários e servem para finalidades determinadas. Retomando as interações, os pedidos implícitos de explicação refletem esse processo de construção desses acordos que visam a sustentar a interação para que eles possam se compreender reciprocamente. Assim, pouco a pouco, a audiência ganha sentido para o jurisdicionado graças ao seu esforço para compreendê-la; esses passam à qualidade de membros, pois as conversas se valem dos mesmos accounts, isto é, das mesmas bases cognitivas para que a finalidade prática da interação seja alcançada. A remissão às situações vividas durante a audiência provê exemplos práticos da finalidade da interação para as pessoas.

No quadro deste trabalho, chamo de moral aquilo que se opõe ao direito técnico a fim de retomar a antiga distinção usada pelos juristas, ou seja, o que pertence à técnica do direito contra o senso comum moral.

Os profissionais do direito interpretam esse senso moral para explicarem-se de maneira a se fazer entender pelos jurisdicionados, e fazem-no igualmente com as respostas dos jurisdicionados, expressas em uma linguagem comum. O exercício cognitivo 
é duplo, pois é preciso que as questões e as respostas sejam compreensíveis por todos. No exemplo em que o juiz explica sua própria pergunta, ele procura esclarecer as opções do jurisdicionado mostrando os resultados práticos, uma vez que saber a data do julgamento ou dar explicações não são ações previstas no texto da lei. Descritas dessa forma, essas opções não são jurídicas. Mas o juiz se vale disso para se tornar compreensível através da linguagem comum, utilizando expressões indexicais que familiares ao senso comum.

A explicação da decisão no último caso mostra a mesma lógica. No momento em que o juiz anuncia sua decisão, nenhuma regra de direito protege mais as mulheres em casos que provoquem mais de oito dias de interdição para o trabalho; essa é, porém, a fórmula que o juiz anuncia para aplicar o direito penal. Utilizando a cena observada por todos, isto é, um homem mais forte contra uma mulher mais fraca diante da barra, o juiz demonstra como esse cenário é relevante e também um meio para explicar sua decisão. Isso é utilizado como um account no seu trabalho de interpretação, que assim transforma a regra jurídica em regra moral. O que é importante é que o trabalho de interpretação utiliza o contexto como fonte de demonstração de suas explicações, pois ele é sempre dinâmico.

Em todos os casos, a utilização de uma linguagem familiar aos jurisdicionados é imprescindível, pois se constata que a interação utiliza uma linguagem comum, personalizando as opções como se o direito fosse um problema de regras individuais criadas pragmaticamente segundo o caso que está sendo discutido. A utilização de princípios morais individualizados como atalho é feita graças aos accounts que pertencem a um saber comum. Não é necessário ensinar ao jurisdicionado como funciona a instituição judiciária, porque as explicações não se fazem sobre as mesmas bases cognitivas. O consenso é provisório e precário, a fim de realizar uma finalidade prática.

A interpretação do direito para essa finalidade não possui o mesmo sentido que os juristas utilizam para elaborar uma compreensão aprofundada sobre o sentido do direito, ao contrário; ela esta relacionada ao que os juristas práticos do direito chamam de senso prático. Na realidade, essa competência pragmática serve para realizar um trabalho que une o saber técnico jurídico do magistrado com a capacidade de explicar seu trabalho de uma maneira comum. Além disso, esse trabalho interpretativo é realizado para explicar aos jurisdicionados as opções juridicamente possíveis e, em troca, compreender as respostas que lhe são dadas. O sentido prático é permitir ao jurisdicionado se tornar um membro, utilizando expressões que funcionam como accounts a fim de desenvolver o trabalho da audiência.

A descrição dessas duas atividades cognitivas permite o diálogo entre juristas e leigos sobre as mesmas bases em uma audiência judiciária. A aprendizagem e o uso dos princípios morais são na realidade atividades reflexivas engendradas pela interação, porque uma atividade depende da outra para se realizar.

Por reflexividade, Coulon entende: 
as práticas que, ao mesmo tempo, descrevem e constituem um quadro social. É a propriedade das atividades que pressupõem ao mesmo tempo que elas produzem a mesma coisa. No transcorrer de nossas atividades comuns, nós não prestamos atenção ao fato que, ao falar, nós construímos e tornamos observáveis ao mesmo tempo, pouco a pouco com nossos enunciados, o sentido, a ordem, a racionalidade do que nós estamos fazendo neste momento. As descrições do social transformam-se, assim que são ditas, em partes constitutivas do que elas descrevem. (COULON, 1993, p. 37) (grifos meus)

Durante as interações, as duas atividades cognitivas acontecem para permitir a realização do trabalho da audiência que é a instrução do processo. A fim de não escapar desse escopo, os membros criam maneiras de se compreenderem reciprocamente, apesar da assimetria da interação. Eles são então reflexivos, na medida em que um esforço engaja o outro.

Ao contrário do que se poderia esperar, as diferenças institucionais dos membros não são um obstáculo à interação. Eles poderiam se utilizar delas para evitar as interações, mas as observações constataram que a maior parte os juízes explica o direito para que se façam compreender e para saber o que os jurisdicionados querem. O poder de presidir e julgar é raramente utilizado para evitar as explicações aos jurisdicionados.

Os accounts favorecem a atualização dos sentidos que as pessoas dão às expressões; os dois lados realizam um reajuste analógico das experiências vividas, ou seja, o trabalho interpretativo é feito de formas diferentes pelos juristas e pelos leigos. Esse é um reajuste das experiências vividas porque os membros utilizam os accounts para estabelecer as bases comuns do dialogo utilizando o conhecimento orientado pelo contexto. As pessoas compartilham o sentido contextual das regras jurídicas “ajustando e aumentando seu estoque de experiências” (SCHUTZ, 1962, p. 105). Finalmente, esse reajuste é analógico pois cada um pode desenvolver sua própria maneira de realizar o trabalho interpretativo, criando ferramentas cognitivas que lhes permitem melhor compreender a situação.

A reflexividade é, assim, o que constitui o quadro social da audiência, pois os membros realizam atividades cognitivas para permitir a interação que, inicialmente, não se realiza sobre as mesmas bases (a linguagem e o conhecimento) - porém, todos fazem um esforço mútuo para se entender.

A interação entre os juristas e os leigos realizadas pelas diferentes atividades cognitivas produz accounts. O que aconteceu com um jurisdicionado é o ponto de partida comum para um outro que se segue. Eles então se servem disso para facilitar os diálogos e a compreensão a fim de que o trabalho seja feito. Desse modo, as audiências judiciais são constituídas pelas razões e pelo comportamento do juiz, que é publicamente observado e levado em consideração pelas pessoas, como explica Lynch (1998, p. 
125). Assim, as regras jurídicas não são as únicas orientadoras do trabalho dos juristas, mas sobretudo os constrangimentos contextuais que atualizam o conhecimento abstrato que se tem acerca dessas regras.

A reflexividade explica, pois, como é possível que essas atividades cognitivas se encadeiem a fim de produzir a realização das finalidades práticas. O trabalho da audiência é propício ao estudo dos profissionais do direito, pois nós podemos observar como o domínio de um conhecimento profissional se realiza no desenrolar das atividades práticas durante as interações com os leigos.

\section{CONCLUSÃO}

A cena judiciária é um lugar de pesquisa onde as interações assimétricas podem ser observadas. Isso, porém, não é simples, porque é preciso mostrar como se pode observá-las dentro de um fórum.

A abordagem escolhida é uma alternativa às abordagens sociológicas correntes. A partir de um trabalho etnográfico que permite a descrição densa de um meio que é mal conhecido, pode-se revelar elementos que favorecem a interação e o modo como ela faz parte também do trabalho rotineiro de audiência. O encontro nos permite assim observar os fenômenos que só são verificáveis naquele momento. A forma pública e transparente pela qual se estruturam institucionalmente as audiências judiciais na França permite tanto ao pesquisador quanto ao jurisdicionado aprender o sentido das regras jurídicas no contexto em que elas são aplicadas.

Pude identificar dois fenômenos distintos: a aprendizagem pelo jurisdicionado e a interpretação das regras jurídicas em uma linguagem comum pelos juristas. Eles se tornam objetivos durante a comunicação pois facilitam as trocas que, de um ponto de vista prático, são importantes para todos. A situação que poderia ser complicada, ou até mesmo impeditiva, é na realidade realizada de modo inventivo e criativo. Esses momentos da vida cotidiana nos mostram como as pessoas criam maneiras para tornar tais situações, que poderiam se supor improváveis, possíveis.

As interações desencadeiam uma série de atividades práticas e intelectuais reflexivas, ou seja, um fenômeno só é possível na medida em que o outro acontece. A inventividade é de fato uma característica dessas atividades, pois a maneira na qual cada um realiza seja a aprendizagem, seja a interpretação pode ser inteiramente original. $\mathrm{O}$ ajuste analógico das experiências vividas designa essa qualidade imaginativa e inventiva que se observa. O dinamismo de tal encontro não advém do fato de que as pessoas somente reagem, mas de que elas colocam sempre novas questões que necessitam de novas respostas, o que se pode constatar se observarmos atentamente. O trabalho da audiência revela então os elementos cognitivos que mostram como o direito se fabrica a partir das relações que os juristas mantêm com os jurisdicionados, abrindo possibilidades para compreender as formas pelas quais se produz as deci- 
sões judiciais.

: ARTIGO APROVAdo (02/12/2013) : RECEBIDO EM 30/07/2012

\section{NOTAS}

* O autor agradece à Michel Miaille por suas sugestões ao texto e às críticas de seus colegas Fernando Fontainha, Sylvain Barone e Alan Rangel. Uma primeira versão deste artigo foi apresentada no $3^{\circ}$ Congrès de l'Association Française de Sociologie, onde foi discutido por Laurent Willemez. Uma primeira versão francesa deste artigo foi publicada no volume 13 da revista Mediterranean Journal of Human Rights em 2009.

1 No que concerne esse artigo, os dados foram coletados a partir de observações de audiências presididas por juízes de proximidade que têm uma formação jurídica, pois pude realizar entrevistas aprofundadas com a maioria deles (GERALDO, 2011).

2 Os tradutores do texto mantiveram o jogo de palavras do texto original com a palavra "account-able".

3 No original, a expressão utilizada é “accountable-matters-for-all-practical-purposes”(N. do T.).

\section{REFERÊNCIAS BIBLIOGRÁFICAS}

ACKERMANN, W.; BASTARD, B. Innovation et gestion dans l'institution judiciaire. Paris: Librairie générale de droit et de jurisprudence, 1993.

ALIMENA, C. M.; AZEVEDO, R. G. DE. Era uma vez um Juizado de Violência Doméstica e Familiar contra a Mulher. In: AZEVEDO, R. G. de (ed.). Relações de Gênero e Sistema Penal. Porto Alegre: EDIPUCRS, 2011.

AMORIM, M. S. DE; KANT DE LIMA, R.; BAUMANN BURGOS, M. (eds.). Juizados especiais criminais: Sistema judicial e sociedade no Brasil. Niterói: Intertexto, 2003.

ATKINSON, J. M.; DREW, P. Order in court: the organisation of verbal interaction in judicial settings. Londres: Humanities Press, 1979.

BANCAUD, A. La haute magistrature judiciaire entre politique et sacerdoce ou Le culte des vertus moyennes. Paris: Librairie générale de droit et de jurisprudence, 1993.

BOIGEOL, A. A formação dos Magistrados: Do aprendizado na prática à escola profissional. Revista ética e filosofia política, v. 2, n. 12, 2010.

BOURDIEU, P. La force du droit. Actes de la recherche en sciences sociales, v. 64, n. 1, 1986.

CAM, P. Juges rouges et droit du travail. Actes de la recherche en sciences sociales, v. 19, n. 1, 1978.

CHRISTIN, A. Jurys populaires et juges professionnels en France. Genèses, v. 65, n. 4, 2006.

COULON, A. L'Ethnométhodologie. 4.ed. Paris: Presses Universitaires de France, 1993.

DREW, P. Contested Evidence in courtroom cross-examination: The case a trial for rape. In: HERITAGE, J.; DREW, P. (eds.). Talk at Work: Interaction in Institutional Settings. New York: Cambridge University Press, 1993. DUPRET, B. L'intention en acte. Approche pragmatique de la qualification pénale dans un contexte égyptien. Droit et société, v. 48, n. 2, p. 439-465, 2001.

Droit et sciences sociales. Droit et société, v. 75, n. 2, p. 315-335, 2010. 
. A intenção em ação: Uma abordagem pragmática da qualificação penal num contexto egípcio. Revista ética e filosofia política, v. 12, p. 109-140, 2011.

EILBAUM, L. "Joga pedra na Geni": da expressão obrigatória dos sentimentos na administração judicial de conflitos no Rio de Janeiro e em Buenos Aires. In: SENTO SÉ MELlO, K.; REIS MOTA, F.; SINHORETTO, J. (eds.). Sensibilidade jurídica e sentidos de justiça na contemporaneidade. Interlocução entre a Antropologia e o Direito. Niterói: EdUFF, 2013.

FERRAZ DE ALMEIDA, F. Ninguém quer ser jurado: uma etnografia da participação dos jurados no Tribunal do Júri. Dissertação de Mestrado - Rio de Janeiro: Pontifícia Universidade Católica do Rio de Janeiro, 2013. GARAPON, A. Bien juger - essai sur le rituel judiciaire. Paris: O. Jacob, 1997. ; SALAS, D. Les nouvelles sorcières de Salem leçons d'Outreau. Paris: Seuil, 2006.

GARFINKEL, H. Studies in Ethnomethodology. New Jersey: Prentice-Hall, 1967. ; SACKS, H. Sobre estruturas formais de ações práticas. Veredas. vol. 16, n. 2, p. 220-256, 2012.

GEERTZ, C. The interpretation of cultures. New York: Basic Books, 1973.

GERALDO, P. H. B. La Proximité au Palais: Une analyse de la socialisation des juges de proximité. Sarrebruck: Éditions Universitaires Européennes, 2011.

. A proximidade dos juízes: Uma análise da socialização de juízes não-profissionais. Revista de Ciênciais Sociais (UGF), v. 17, p. 289-319, 2011.

GOFFMAN, E. Interaction Ritual - Essays on Face-to-Face Behavior. New York: Pantheon Books, 1982.

GONZÁLEZ MARTÍNEZ, E. Organisation et accountability des échanges langagiers lors d'auditions judiciaires. Réseaux, v. 129-130, n. 1, p. 209, 2005

ISRAËL, L. La mise en scène d'une justice quotidienne. Droit et Société, n. 42-43, p. 393-419, 1999.

Robes noires, années sombres avocats et magistrats en résistance pendant la Seconde Guerre mondiale. Paris: Fayard, 2005.

KANT DE LIMA, R. Ensaios de antropologia e de direito: acesso a justiça e processos institucionais de administração de conflitos e produção da verdade jurídica em uma perspectiva comparada. Rio de Janeiro: Lumen Juris, 2009.

LATOUR, B. La fabrique du droit une ethnographie du Conseil d'État. Paris: La Découverte, 2004.

LIBERMAN, K. The social praxis of communicating meanings. Text - Interdisciplinary Journal for the Study of Discourse, v. 19, n. 1, p. 57-72, jan. 1999.

LYNCH, M. Preliminary Notes on Judges' work : The Judge as a Constituent of Courtroom "Hearings". In: TRAVERS, M.; MANZO, J. F. (eds.). Law in Action: Ethnomethodological and Conversation Analytic Approaches to Law. [s.l.] Ashgate Publishing, 1998. p. 99-130.

MICHEL, H.; WILlEMEZ, L. La justice au risque des profanes. Paris: Presses universitaires de France, 2007.

PÉLICAND, A. Les juges de proximité : une étude du recrutement. Paris: Mission de recherche Droit et justice, 2009. Disponível em: <http://www.gip-recherche-justice.fr/catalogue/PDF/rapports/189-RF-Pelicand_juges_proximite.pdf $>$. Acesso em 18 de novembro de 2013.

SCHRITZMEYER, A. L. P. Etnografia dissonante dos tribunais do júri. Tempo Social, v. 19, n. 2, p. 111-129, nov. 2007. SCHUTZ, A. Collected Papers: The Problem of Social Reality. Photomechanical. Haia: Martinius Nijhoff, 1962, v. I SIMONNOT, D. Justice en France: Une loterie nationale. Paris: Editions de La Martinière, 2003.

STARR, J.; GOODALE, M. Practicing ethnography in law: new dialogues, enduring methods. New York: Palgrave Macmillan, 2002.

VAUCHEZ, A. L'institution judiciaire remotivée le processus d'institutionnalisation d'une "nouvelle justice" en Italie (1980-2000). Paris: LGDJ, 2004.

et al. La justice face à ses réformateurs, 1980-2006 entreprises de modernisation et logiques de résistances. Paris: Presses Universitaires de France, 2007.

ZAPPULLI, L. Magistrati si diventa: Etnografia della formazione professionale. Milano: Franco Angeli, 2009.

\section{Pedro Heitor Barros Geraldo}

Rua Presidente Pedreira, 62
Ingá - 24210-470
Niterói - RJ - Brasil
pedrogeraldolaid.uff.br
PRofessor Adjunto do Departamento de Seguranca Pública da Faculdade de Direito da Universidade Federal Fluminense

DOUTOR EM CIÊNCIA POLÍtICA PELA UnIVERSITÉ MONTPELLIER 1 Pesquisador do INCT-InEAC (InStituto de Estudos Comparados em Administração Institucional de Conflitos) 
